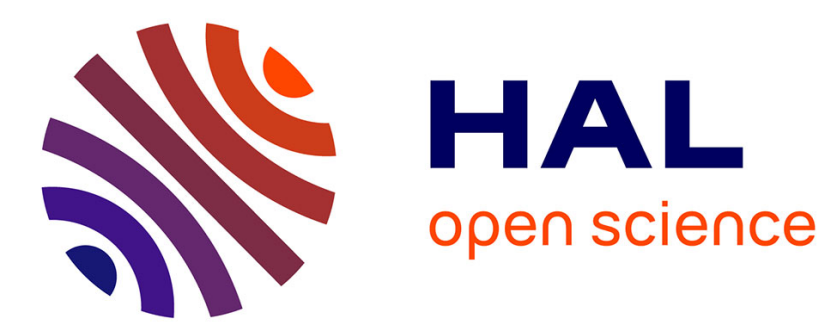

\title{
Open Innovation Practitioners Mindset on Risk
}

Paula Urze, João Rosas, Alexandra Tenera, Luis M. Camarinha-Matos

\section{To cite this version:}

Paula Urze, João Rosas, Alexandra Tenera, Luis M. Camarinha-Matos. Open Innovation Practitioners Mindset on Risk. 20th Working Conference on Virtual Enterprises (PRO-VE), Sep 2019, Turin, Italy. pp.103-114, 10.1007/978-3-030-28464-0_10 . hal-02478776

\section{HAL Id: hal-02478776 \\ https://hal.inria.fr/hal-02478776}

Submitted on 14 Feb 2020

HAL is a multi-disciplinary open access archive for the deposit and dissemination of scientific research documents, whether they are published or not. The documents may come from teaching and research institutions in France or abroad, or from public or private research centers.
L'archive ouverte pluridisciplinaire HAL, est destinée au dépôt et à la diffusion de documents scientifiques de niveau recherche, publiés ou non, émanant des établissements d'enseignement et de recherche français ou étrangers, des laboratoires publics ou privés. 


\title{
Open Innovation Practitioners Mindset on Risk
}

\author{
Paula Urze ${ }^{12}$, João Rosas ${ }^{13}$, Alexandra Tenera ${ }^{14}$ and Luis M. Camarinha-Matos ${ }^{13}$ \\ ${ }^{1}$ Faculty of Sciences and Technology, NOVA University of Lisbon, \\ Caparica, Portugal \\ ${ }^{2}$ Interuniversity Center for the History of Science and Technology (CIUHCT) \\ ${ }^{3}$ Center of Technology and Systems (CTS), UNINOVA \\ ${ }^{4}$ Research and Development Unit for Mechanical and Industrial Engineering (UNIDEMI) \\ pcu@fct.unl.pt,jrosas@uninova.pt, abt@fct.unl.pt, cam@uninova.pt
}

\begin{abstract}
Open Innovation is a strategy used by organizations to more promptly comply with the continuous changing market needs and renew their income streams. But its effective achievement depends on the practitioners' ability to assume concrete mindset, like openness, acceptance of risk, talent to build trust and to learn from successes as well as from failures. Based on these assumptions, the paper explores the concept of mindset in open innovation. The approach is twofold combining sentiment analysis over interviews on web documents with semi-directive interviews conducted in IT companies. The results include a characterization of OI practitioners' mindset concerning risk and related elements.
\end{abstract}

Keywords: Open Innovation, Risk Mindset, Collaboration.

\section{Introduction}

Open innovation (OI) is generally seen as a key collaborative strategy that organizations can use to evolve and keep up with the (emergent) market shifts and disruptive technological development. According to several studies, the advantages of OI over lesser open models of innovation have been proven [1, 2]. Despite the diversity of theoretical and empirical research on OI, there seems to exist, in the prevailing discourse of scholars and practitioners, the tendency to exclude the less successful experiences that occur during the innovation process. But such (in) visible side of OI must also be researched, as it is crucial to integrate into the interpretation of OI, not only the advances, successes, and advantages but also the setbacks, failures, and constraints. Such setbacks can be seen as the unintended consequences of the innovation process [3]. But OI requires learning both from successes as well as from failures $[3,4]$.

From an epistemological perspective, more than a final result, it is the trajectory that must be understood to accurately know the OI concept and the elements that 
systemically combine to reach it. There are certainly contingency factors in the process, but there are also structural factors that underlie the social construction of OI. What paths have been taken? What mishaps have been overcome? What choices have been made? Therefore, much more research analysis on this topic is needed at the level of academia. The main goal in this paper is to analyse the mindset of OI practitioners regarding risk and other factors, e.g. trust, incorporating both positive and negative elements of OI in our research. For this, we aim at understanding the narratives and practices of OI actors regarding these elements. Despite recent research efforts, risk in OI lacks a deeper and more systematic analysis $[5,6]$.

We hypothesize that the apparent lack of risk assessment research in literature might be associated with the way the OI concept is usually portrayed, with more favourable narratives in which failures and setbacks are less likely to arise. For this purpose, we proceed to an exploratory analysis of the elements underlying the mindset of OI practitioners, starting with literature analysis. For this, Text Mining and Sentiment Analysis were applied to web documents containing interviews addressing risk in OI, which were available online during the year 2018. Afterwards, semi-directive interviews were conducted with OI practitioners (at the level of company managers) and we finish with results analysis and synthesis.

\section{Background}

Considering the scope and depth of the topics involved in open innovation, in this work we concentrate efforts focusing on the aspects that are mostly relevant to the defined research goals. In this way, we start by revisiting the concept of OI, then moving on to a perspective around the mindset that characterize the practitioners. We conclude this section with a synthesis concerning risk in OI.

\subsection{Revisiting the Concept of Open Innovation}

Open innovation is already a recurring strategy used by organizations to help them keep up with market changes and technological development. According to Chesbrough [7], OI is seen as a more profitable form of innovation, because it can reduce costs, accelerate time-to-market, increase product variability on the market "and create new revenue streams for the company"

In addition to the initial concept of OI as proposed by Chesbrough, OI also appears in the discourse of several scientific areas, generally taking an even further positive tone. The term acquired its more positive view due to its instrumentality from the social, political and material perspectives [3]. This is what we can commonly refer to as the bright side of OI. Although tendentially less visible, while not less relevant, it starts becoming increasingly recognized that the less bright side is also a part of the innovation dynamics, i.e., the other side of the same coin $[8,9]$.

In this sense, organizations, in general, tend to highlight their success cases and hide the mishaps, setbacks and failures during their OI projects. Whenever these are 
reported, they are shown as sporadic episodes, without meaningful relevance in the innovation dynamics. But, to adequately tackle the OI concept, it is crucial to incorporate those less publicizable elements. Such critical aspects are of paramount importance to innovation in general, and to OI in particular, as difficulties, and often the failures, frequently allow reaching increased achievements in knowledge and results. Then, we need to focus also at the Innovation practitioners. To walk the path of OI, practitioners need to aggregate several OI compatible attitudes, allowing them to be able to benefit from successes and learn from failures.

\subsection{The Open Innovation Mindset}

When Chesbrough colloquially placed the question "What is open innovation?", he answered that it mainly means having a much more open mindset and much more engaged with both the inside and outside world[10].

Furthermore, as mentioned by Björling in [11], participating in OI requires having some important attitudes, namely, that we must be "open to change", because the world is constantly changing. We need to "embrace creativity", recognizing that instead of "management processes" and "organizational structures," the starting point of OI is creativity, which requires a certain type of culture and organizations to make it possible. Another important facet is to have the ability and courage to "think big" and proceed beyond current norms and truths in the marketplace. This implies extending beyond normal/ordinary thinking and analysis. The author also states that OI implies to "show courage" to constantly rethink how things can be done. Finally, he argues that in OI, we must "think and act quickly" since innovations typically comprise agile processes.

In this regard, mindset can be understood as having a way of thinking or having psychological predispositions, which are tied to corresponding attitudes, ideas, beliefs and patterns of behavior. As such, it is scientifically important and strategically interesting to determine and accurately characterize the OI practitioners' mindset.

\subsection{A Risk Perspective in Open Innovation}

To properly establish an OI risk perspective, it is important to start by contrasting the two innovation models, internal and open.

Within company boundaries, innovation projects include practitioners who are subjected to management and supervision processes, in which risk control mechanisms can be used, allowing to deterministically anticipate and circumscribe contingencies and failures. Therefore, the "internal" innovation, typically supported by Research and Development Innovation (RDI) management systems and projects, has been already consolidated $[12,13]$ as well as the internationally consolidated risk assessment methods and tools for risk evaluation [14] within a company. In short, despite its intrinsic uncertainty and significant rate of products failures, internal innovation can be handled within management practices. 
On the other hand, OI is characterized by its practitioners' autonomy in an environment which favors creativity, knowledge sharing, collaboration, and trustworthiness. As such innovation process are much more complex and much more unpredictable. Furthermore, due to partners' self-interests, relatively frequent conflicting goals and lack of preparedness, there is a growing risk of failures. On each failure, both resources and time are lost. For instance, intellectual property can be taken away and used by other actors for their benefit. In this sense, risk assessment is considered far more challenging in OI contexts. Furthermore, as mentioned in [15], the failure rate of a new product's development is around $35 \%$, and this just considering the products that could reach the market phase. Other sources $[16,17,18]$ report that failure rate can go up to $80 \%$ if the failures in the preliminary stages are also considered. Therefore, although risk models are difficult to apply in OI, their effective use could have significant impacts on OI outcomes.

\section{Exploratory Study}

In this chapter, we describe the methodological approach applied to characterize the mindset of practitioners in OI. The approach includes two distinct methods.

As illustrated in Fig. 1, the first method involves Text Mining and Sentiment Analysis performed on interviews recorded in on-line documents provided throughout the year 2018. The second method consisted on semi-directive interviews conducted CEOs and CTOs, who are OI practitioners.

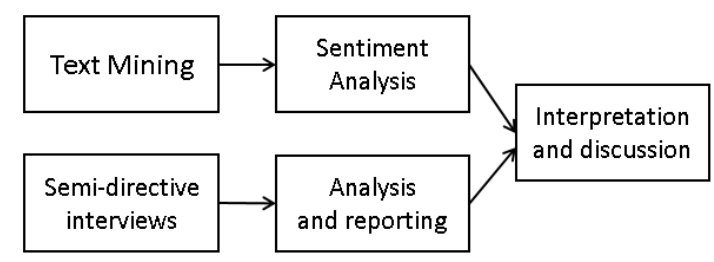

Fig. 1. Phases in our research method.

Sentiment Analysis is a widely used method particularly in the Social and Behavioral Sciences, as well as in Web-based services for characterization of online information and users from Online Social Networks [19, 20, 21]. The semi-directive interview can be seen as a methodologically adequate technique to more deeply enquired entrepreneurs and managers regarding OI, as it allows collecting information of qualitative nature, through interaction with interviewees, in which the discourses, feelings, emotions, and contexts intersect together. Therefore, sentiment analysis of online interview documents (extensive analysis) combined with face-to-face interviews results in a methodological approach that enhances the interpretation framework. 


\subsection{Exploratory Analysis of Online Documents}

\subsubsection{Research Method Description}

The research method followed in this phase involved several steps which are represented in Fig. 2. Firstly, we searched documents containing interviews regarding OI. Then these documents were downloaded to a local repository to be further checked and analyzed, and in the final steps subject to Text Mining and Sentiment Analysis.

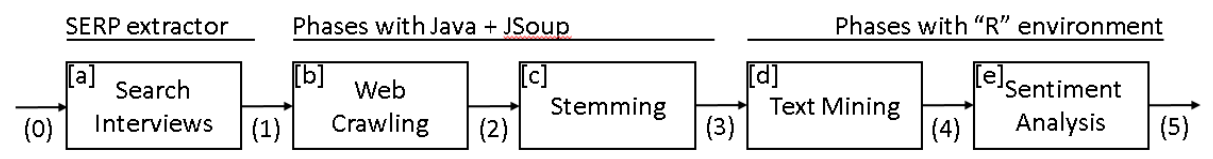

Fig. 2. Steps comprising the Text Mining and Sentiment analysis of interviews.

The interviews were collected from online documents made available during the year 2018, with the search engine, "Google Search". We searched for documents of that year that contained the terms "open innovation" and "interview." This search performed in step (a) resulted in 18,093 URL links of potential interview documents.

In the next step (b), each site was visited, and its content downloaded and recorded in a local file. For this part, we developed a small Java application integrating the JSoup library [22] for extracting the documents' contents. However, after inspecting the content of some documents, we found that many of them did not correspond to interviews. Thus, it was also developed a filter for identifying only valid interview documents. This filter is composed of a regular expression which tracks sentences ending with a question mark. The rationale is that if each document arose as a result of a search with the keyword "interview," the odds of being a document with an interview is higher. If the document contains questions, then it must be an interview. After inspecting a sample of the downloaded documents, we verified that documents with at least five questions were interviews. To reduce false positive documents, we collected documents with at least ten questions inside. The next step included the elimination of "stop words" and the stemming of the documents' terms (step (c)) [23]. During the stemming transformation, if each yielded word did not belong to the dictionary, then we considered the original word, as we needed valid words for the sentiment analysis part. The remaining steps are synthesized in Table 1.

In steps (d) and (e), we relied on the "R" environment [24], for its good features on Text mining, including Sentiment Analysis. With R, we proceed to the determination of the document-term matrix, but its transformed form, using the "inverse document frequency" formula (Tf-idf), which reduces the importance of terms that are too common across the documents. Phase (e), corresponding to the sentiment analysis, was also performed within the $\mathrm{R}$ environment, using the scripts illustrated and described in [25]. 
Table 1. Description of Steps involved in text mining and sentiment analysis

\begin{tabular}{|c|c|c|}
\hline Inputs & Steps & Description \\
\hline$(0)$ & & Keyword search: "open innovation" AND interview, for the year 2018 \\
\hline & (a) & $\begin{array}{l}\text { Find documents with Google Search engine. Considering documents with } \\
\text { at least ten questions. }\end{array}$ \\
\hline (1) & & Set of URLs obtained with a SERP extractor. \\
\hline & (b) & $\begin{array}{l}\text { Small Java App with JSoup that visits each URL and saves its content in } \\
\text { a local filesystem. Non-English documents are eliminated. }\end{array}$ \\
\hline (2) & & Collection of documents in a folder named "Corpus". \\
\hline & (c) & $\begin{array}{l}\text { Elimination of Stop words and stemming. Stemming of each word is } \\
\text { considered only if the transformed term is still a word in the dictionary. }\end{array}$ \\
\hline (3) & & Collection of documents in a folder named "Corpus". \\
\hline & (d) & $\begin{array}{l}\text { Download corpus; DTM determination "tidytext" and "tm" libraries } \\
\text { inside R environment. }\end{array}$ \\
\hline (4) & & Matrix dtm_tfidf. \\
\hline (5) & (e) & $\begin{array}{l}\text { Application of sentiment analysis. } \\
\text { Plot sentiment analysis chart. }\end{array}$ \\
\hline
\end{tabular}

\subsubsection{Obtained Results}

Fig. 3 presents the chart obtained during sentiment analysis. An initial general interpretation suggests that there is a generally positive attitude towards OI.

On the positive side, such words as "capability", "patient", "award", "sustainability", "flexibility", "talent", "master" and "skill" match with the more frequent sentiments detected, followed by the term "trust", which corresponds to an important sentiment in collaboration. The other terms appearing on the positive side, namely "skills", "agility", "competitive", "intelligence" and "creativity" allow us to, in principle, confirm the kinds of attitudes, or mindset, related to open innovation, as portrayed in section 2.2.

On the negative side, the sentiment analysis highlighted several terms that also meet the topics addressed in this work. The term "risk" is the most important element appearing on the negative sentiment analysis, which raises a question by itself. Why is risk the most cited element from the interviews? Considering that Sentiment Analysis of these interviews yields a more positive than negative tone, perhaps OI participants feel that in spite of the dangers, OI is a strategy that is worth to take. This result supports the argument that risk is an intrinsically major concern of OI. It also might mean that risk in OI deserves much more attention by researchers. Other terms that may also be tied to risk are "disruption" and "conflict", which are concerns that are known to increase the risk of Open Innovation partnerships failure.

The term disruption is interesting in this regard. Costumers benefit from "disruptive technology", which drive the creation of innovative products, so disruptiveness is seen a positive element. Researchers of innovation, and similarly in other areas, like to conceive innovation as a "disruptive phenomenon", so disruptiveness is seen in a more positive mood. However, companies may perceive "disruptive" events with more cautious eyes. We would say that "disruptive technologies" or similar situations may frequently cause both industrial and market shifts that companies may find threatening and detrimental for their business models. Therefore, from the companies point of view "disruptive" cases might be seen as negative. 


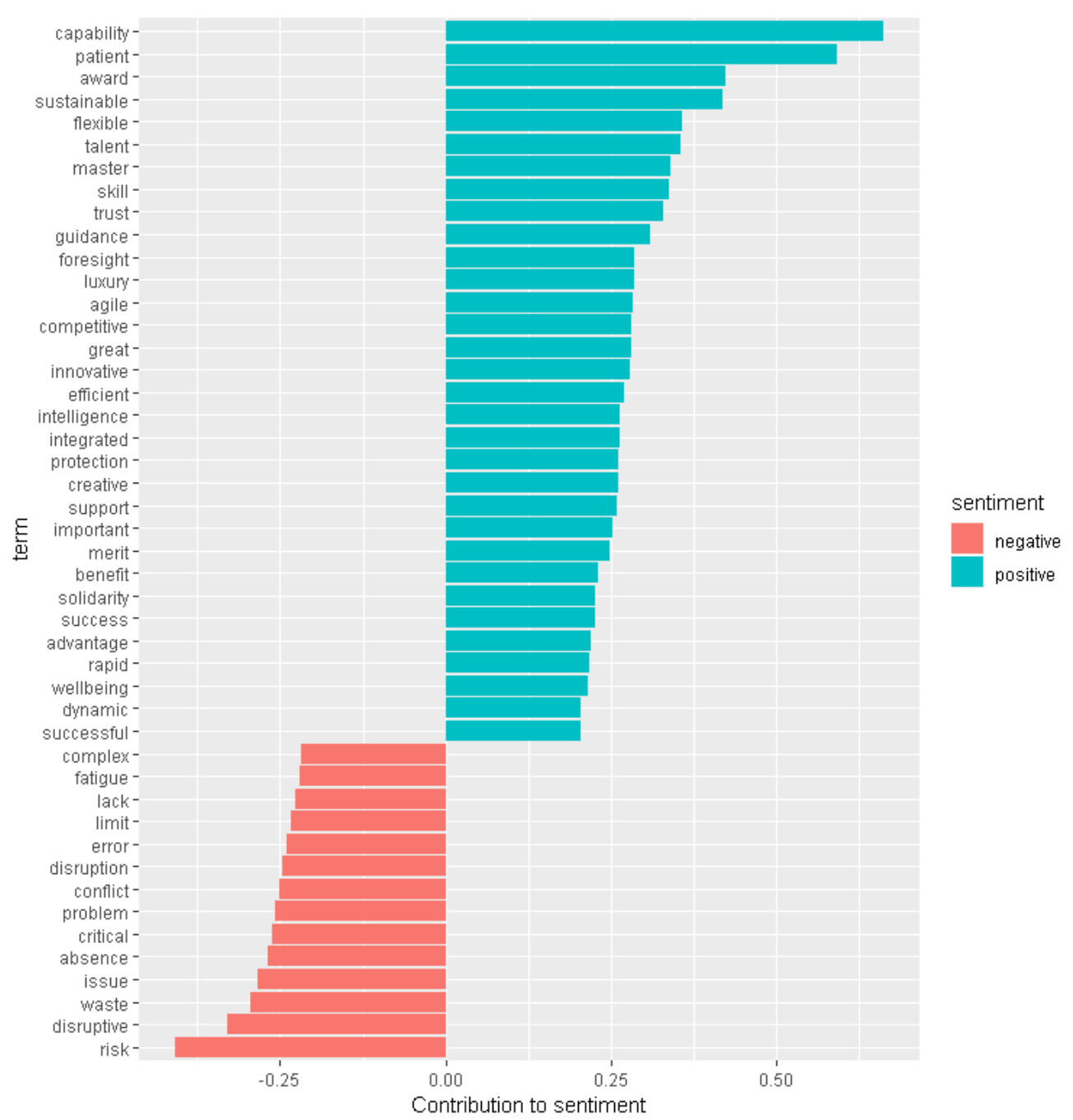

Fig. 3. Sentiment analysis plot

\subsection{Interviews with OI Practitioners}

\subsubsection{Methodological Steps}

In the scope of empirical research, we complementarily conducted semi-directive interviews with three CEOs and two managers from four information technology (IT) companies. The interviews were carried out during March and April 2019. We defined several questions oriented to OI practices in companies' contexts (interview script). The 
collection of qualitative information from the interviewees' discourses allowed to complement the sentimental analysis and the construction of an interpretative framework based on the experience of OI practitioners. The way to reach companies was based on the technique of "snowball", taking as a starting point a company, whose practice of OI is already a case of widespread scientific dissemination [26].

Our goal was to obtain more in depth, rather than extensive, information regarding OI. Qualitative questions constitute a reflexive process that gives density to the analysis and allows one to gauge the "microscopic" details [27] from the understanding of OI practitioners.

\subsubsection{Obtained Results}

Based on the testimonies collected from the selected OI practitioners, we prepared a content analysis grid for the interviews, covering a set of categories considered relevant for our research aims, namely, practices, risk, trust, contracts, and partnerships. These categories were empirically chosen, as they were recurring elements in the interviewed practitioners' discourses. In each of these categories, we included the recording units of the various interviews [28], which we interpreted as negative or positive discourses, and we converted them into enumeration units based on the occurrence of the records in the respective categories (Table 2). From weighting them, we may conclude a more positive than negative tone considering OI.

Table 2. Categories from the semi-directive interviews

\begin{tabular}{|c|c|c|c|c|c|c|}
\hline Open Innovation & \#Practices & \#Risks & \#Trust & \#Contracts & \#Partnerships & SCORE \\
\hline Positive opinions & 8 & 8 & 4 & 5 & 5 & 30 \\
\hline $\begin{array}{l}\text { Negative } \\
\text { opinions }\end{array}$ & 4 & 5 & 2 & 1 & 2 & 14 \\
\hline \multicolumn{6}{|c|}{ Overall Sentiment } & Positive \\
\hline
\end{tabular}

In the remaining of this section, we present the more in-depth and richer insights provided by the interviewed OI practitioners.

\section{Practices and Partnerships}

From the analysis of the interviews, we obtained relevant information that allows deepening the aspect regarding the mindset of the participants in open innovation. One of the interviewees mentions that "OI is a virtuous concept, enabler of various businesses, but that from concept to practice goes a great distance." He added that "we need to have a mindset for open innovation". There is a clear idea that practicing OI requires a specific form of thinking and a particular attitude. It means accepting the risk, vulnerability, and uncertainty.

OI is, in general, seen from a positive perspective, "several initiatives fit into open innovation. We have an area dedicated to identifying possible partners, whether national or international. The fact that we open and share with other companies we all win. We are not going from scratch; we start from a more advanced level". But it is 
also said that "they share little of the failures, which is inevitable and integral and essential for us to reach the part of success. It is a very great wealth. There are situations of contingency success".

Nevertheless, the experiences are successful; there are paths with advances and retreats until the final result. As the interviewee stresses, both negative and positive experiences are important and should be shared as they allow for joint learning to deal with the complexity of problems and solutions.

\section{Risk, Trust, and Contracts}

The OI practitioners' discourse points to different practices taking into account the structure of the company and the type of business. There is, however, a coincident narrative in the risk perspective. More risk requires more trust. And the idea that $\mathrm{OI}$ is risky is consensual. As the interviewee adds "there is no innovation without risk".

The words of the CEOs make us confirm that the relationship with the partners is essential to the existence of trust, as a way to minimize the risk. It is crucial that the development of the business takes place within a calculated risk framework, as one of the interviewees indicates, which allows for the establishment of commitments and guaranteeing the delivery of products/services by the expectations of the clients. "When we go with other companies, we have more risk, in principle. We have a very close relationship, but we have no control. It is important to look at the risk to do the math and say is between 40 and 50."

Risk arises with a double face, the challenge of the business itself, and the business in the framework of an OI paradigm, and the risk that must be safeguarded in the relationship with partners. One of the aspects that are repeatedly underlined is precisely risk acceptance. Nevertheless, there are nuances in terms of risk in the interviewees' discourse. Important in the study of trust is the issue of risk. The border of trust can be defined by mistrust. It is the development of trust that lays the foundation for trusting one partner more than another and deciding the level of risk to which it is prudent to incur.

There are referred forms of contracting that define rules of understanding between the partners and with the customers regarding the sharing of intellectual property. As one of the interviewees says "we sign agreements with all companies".

There is, however, the feeling that more important than these contracts are the behavior of partners and the building of relationships of trust. "We have a lot of memorandums of understanding (MoU) that are practically replicated from each other, but it's worth it." Another interviewee adds: "It is important to have trusted partners to embrace the projects." In this way, risk containment through formal means (contracts) can be used as a device not to eliminate its exposure to risk, but to reduce exposure. As mentioned before, there is no OI without risk. In conclusion, creativity and pro-activity are characteristics that, in one way or another, refer to: we must go further, search for new paths, new methodologies, new approaches, and not be afraid to embrace new projects, ideally with partners in which we have trust, but when it does not happen, the stance is to go to the market to look for new partners to respond to new business. 


\section{Discussion and Conclusions}

\subsection{Summary of the Developed Work}

In this paper, we present a research approach for exploring the mindset for risk in OI The approach involved the application of two specific methods: the first one was based on the application of "text mining" and sentiment analysis performed on documents containing interviews, which were provided online during the year 2018. The second method consisted of semi-directive interviews addressed to OI practitioners.

\subsection{Critical Analysis of the Application of the Two Methods}

Based on the results of both research methods, it was emphasized that participants take a more positive than a negative stance towards OI, which is consistent with the theoretical and empirical manifestations mentioned in the literature.

From the analysis of interview documents available online, the positive side of sentiment analysis includes the trust term, which represents a crucial attitude in collaboration and OI. The risk appeared as the term that most contributes to the negative side of the sentiment chart.

From the CEOs interviews, the main idea that stands out is a relatively strong will to engage in innovation, although with safeguards that each practitioner applies as a way to mitigate risk. But they embrace it, as one stated, "There is no innovation without risk".

These results give a better understanding of the main mindset, positive and negative perspectives, regarding OI, from which it was possible to determine that risk plays an important role. There is also an apparent dissonance between the importance of risk in OI and the emergence in their research by academics.

Therefore, the combination of both research approaches and the literature confirm the idea that entrepreneurs should display OI enhancer mindsets, which maximize the success, like being open, trust partners, taking risks, adapt to changes, challenge tradition, and collaborate.

As a final remark, despite the theoretical character associated with the OI, it is through the interpretation of social practices, incorporating positive and negative occurrences, that the very concept of open-innovation achieves greater conceptual maturity.

We identified potential lines of research for future work. One such line consists of exploring the trust versus risk dichotomy that was recurrent in the results provided from both research methods. Although a more challenging goal, we also aim to develop work to integrate the OI mindset concept in risk assessment and into management processes.

\section{Acknowledgments.}

A special thanks to A-to-Be, Do iT Lean, Fordesi and MakeWise companies for the valuable contributions for the performed research. 
This work has been partially supported by Interuniversity Center for the History of Science and Technology (CIUHCT) (Portuguese FCT-PEST program UID/HIS/00286/2019) Center of Technology and Systems (CTS) - Uninova, (Portuguese FCT-PEST program UID/EEA/00066/2019), and UNIDEMI - Research and Development Unit for Mechanical and Industrial Engineering (Portuguese FCTPEST program UID/EMS/00667/2019).

\section{References}

1. Chesbrough, H. (2004) Managing Open Innovation, Research-Technology Management, 47:1, 23-26, DOI: 10.1080/08956308.2004.11671604

2. Felin, T., \& Zenger, T. R. (2014). Closed or open innovation? Problem solving and the governance choice. Research policy. 43(5), 914-925.

3. Godin, B. \& Vinck, D. (2017) Introduction: innovation - from the forbidden to a cliché in Benoît Godin, Dominique Vinck (Eds.) Critical Studies of Innovation: Alternative Approaches to the Pro-Innovation Bias, Edward Elgar Publishing.

4. Sveiby, K. (2017) Unattended consequences of innovation n Benoît Godin, Dominique Vinck (Eds.) Critical Studies of Innovation: Alternative Approaches to the ProInnovation Bias, Edward Elgar Publishing.

5. Rosas, J., Macedo, P., Tenera, A., Abreu, A., \& Urze, P. (2015, October). Risk assessment in open innovation networks. In Working Conference on Virtual Enterprises (pp. 27-38). Springer, Cham.

6. Rosas, J., Urze, P., Tenera, A., Abreu, A., \& Camarinha-Matos, L. M. (2017, September). Exploratory study on risk management in open innovation. In: Collaboration in a Data-Rich World, IFIP AICT 506, pp 527-540, Springer. DOI: 10.1007/978-3-319-65151-4_47.

7. Chesbrough, H. (2011), Everything You Need to Know About Open Innovation, https://www.forbes.com/sites/henrychesbrough/2011/03/21/everything-you-need-toknow-about-open-innovation/\#741310f175f4, seen at 2019/04/20.

8. Vinck, D. (2017) Learning thanks to innovation failure in Benoît Godin, Dominique Vinck (Eds.) Critical Studies of Innovation: Alternative Approaches to the ProInnovation Bias, Edward Elgar Publishing, 2017.

9. Martin, B. R. (2013) Innovation Studies: An Emerging Agenda, Fagerberg, Jan; Martin, Ben R.; Andersen, Esben Sloth (Eds.) Innovation Studies: Evolution and Future Challenges, Oxford.

10. A growth strategy for the digital age: the key is Open Innovation, Fujistu, (2018), https://www.fujitsu.com/pt/vision/insights/201805event/, seen at 2018/04/20

11. Björling, M. E. "5 key steps to creating an innovation mindset", https://www.ericsson.com/en/blog/2018/5/5-key-steps-to-creating-an-innovationmindset, seen at 2018/04/10.

12. NP 4457 (2007) Gestão da Inovação, Desenvolvimento e Inovação (IDI) / Management of Research, Development and Innovation (RDI): Requisitos do sistema de gestão IDI / Management system requirements of RDI activities, IPQ Technical Committee CT169, Instituto Português da Qualidade (IPQ).

13. NP 4458 (2007) Gestão da Inovação, Desenvolvimento e Inovação (IDI) / Management of Research, Development and Innovation (RDI): Requisitos de um projeto de gestão 
IDI / Requirements for RDI project, IPQ Technical Committee CT169, Instituto Português da Qualidade (IPQ), 2007.

14. IEC 31010 (2009) Risk management - Risk assessment techniques, Technical Committee, ISO/TC 262, ISO/IC.

15. Castellion, G., \& Markham, S. K.: (2013) Perspective: new product failure rates: influence of argumentum ad populum and self-interest. Journal of Product Innovation Management, 30(5), 976-979.

16. Simoons, P.: The $80 \%$ rule of business partnerships. (2013) https://www.petersimoons.com/2013/07/the-80-percent-rule/. Seen on 2017/03/25

17. Fisher, A.: Why most innovations are great big failures (2014). http://fortune.com/2014/10/07/innovation-failure/. Seen on 2017/02/20.

18. Martinez, M. G. (Ed.). Open innovation in the food and beverage industry. Elsevier. (2013). 12.Hewitt-Dundas, N., \& Roper, S.: (2017) Exploring market failures in open innovation. International Small Business Journal, DOI: 10.1177/2F0266242617696347.

19. Liu, B. (2010). Sentiment Analysis and Subjectivity. Handbook of natural language processing, 2(2010), 627-666.

20. Farhadloo, M., \& Rolland, E. (2016). Fundamentals of sentiment analysis and its applications. In Sentiment Analysis and Ontology Engineering (pp. 1-24). Springer, Cham.

21. Kaushik, A., \& Naithani, S. (2014). A Study on Sentiment Analysis: Methods and Tools. International Journal of Science and Research (IJSR).

22. jsoup: Java HTML Parser (2018), https://jsoup.org/, seen on 2019/03/20

23. Aggarwal, C. C., \& Zhai, C.: (2012) A survey of text clustering algorithms. In: Mining text data (pp. 77-128). Springer US.

24. R: A Language and Environment for Statistical Computing (2019), https://www.rproject.org/

25. Silge, J., Robinson, D. (2017). Text mining with R: A tidy approach. O'Reilly Media, Inc. Online book version at https:/www.tidytextmining.com/dtm.html, seen on 2019/04/01.

26. Urze, P., Abreu A. (2012) Knowledge transfer assessment in a co-innovation network, in Working Conference on Virtual Enterprises, IFIP, Springer.

27. Geertz, C. (1973) The interpretation of cultures: Selected essays, New York: Basic Books.

28. Bardin, L. (2008). Análise de conteúdo. Lisboa: Edições 